\title{
The role of afferent renal denervation in renovascular hypertension-another brick in the wall
}

\author{
Márcio Galindo Kiuchi ${ }^{1}$ (D) $\cdot$ Shaojie Chen ${ }^{2} \cdot$ Revathy Carnagarin ${ }^{1}$ - Markus P. Schlaich ${ }^{1,3,4}$
}

Received: 23 January 2020 / Revised: 23 January 2020 / Accepted: 26 January 2020 / Published online: 5 February 2020

(C) Springer-Verlag GmbH Germany, part of Springer Nature 2020

In their elegant study, Lopes and colleagues [6] described that chemical afferent renal denervation (ARD) decreased blood pressure (BP), renal sympathetic nerve activity (rSNA) and reactive oxygen species (ROS) in both kidneys and normalized renal function, proteinuria and activation of intrarenal renin-angiotensin system (RAS) in renovascular hypertensive animals. These data demonstrate that afferent renal nerves are crucial for the maintenance of BP and renal sympathetic hyperactivation, as well as renal function, in the renovascular hypertension model [6].

Heightened sympathetic tone, a well-known risk factor for a range of cardiovascular diseases, is frequently present in patients with essential hypertension and those with chronic kidney disease (CKD) [2, 3]. In both hypertension and renal failure, the mechanisms contributing to the

This article is a commentary to the original article https://doi.org/10.1007/ s00424-019-02346-4

Electronic supplementary material The online version of this article (https://doi.org/10.1007/s00424-020-02354-9) contains supplementary material, which is available to authorized users.

Márcio Galindo Kiuchi

marcio.galindokiuchi@uwa.edu.au; marciokiuchi@gmail.com

1 Dobney Hypertension Centre, School of Medicine - Royal Perth Hospital Unit / Medical Research Foundation, University of Western Australia, Level 3, MRF Building, Rear 50 Murray St, Perth, WA 6000, Australia

2 Cardioangiologisches Centrum Bethanien (CCB) Frankfurt am Main, Medizinische Klinik III,, Agaplesion Markus Krankenhaus, Frankfurt am Main, Germany

3 Departments of Cardiology and Nephrology, Royal Perth Hospital, Perth, Australia

4 Neurovascular Hypertension \& Kidney Disease Laboratory, Baker Heart and Diabetes Institute, Melbourne, Australia hyperadrenergic state are complex and include amongst other reflex and neurohumoral pathways [2, 3, 8]. Moreover, in CKD, sympathetic overactivity is already evident in the early stages and shows a direct relationship with the progression of renal impairment [11].

$\mathrm{BP}$ control is principally achieved by the integrated renalendocrine systems that balance volume and sodium homeostasis. Renal sympathetic innervation consists of efferent sympathetic fibres arising from the central nervous system towards the kidneys, as well as afferent sensory fibres arising from the kidneys and projecting to the hypothalamus. Heightened sympathetic outflow to the renal vascular bed reduces renal blood flow, releases renin, thus activating the renin-angiotensin-aldosterone system (RAAS), triggering vasoconstriction and enhancing tubular reabsorption of urinary sodium and water (Fig. 1). These mechanisms initiated by increased efferent SNS activity ultimately result in elevation of BP. The reduced renal blood flow stimulates the renal sensory nerves (afferent) with the consequence of increased central SNS outflow. Both central and local increase in SNS activity affect a large number of these pathways and have been associated with hypertension and its progression [4].

Afferent renal nerve ablation leads to the mitigation of sympathetic signals arising from the kidneys to the brain, which per se lowers central sympathetic outflow ultimately reducing the efferent sympathetic nerve signalling to key organs. Beyond the already expected BP-lowering effect after renal afferent fibre disruption, Lopes and colleagues' findings provide us with a persuasive explanation about how a catheter-based renal denervation (RDN) approach may have caused the halt [9] or even improvement in renal function [5] that was noticed in patients with hypertension and CKD, as well as the reduction in albuminuria [5, 9] - an independent risk factor for cardiovascular events [7] and a predictor for the progression of CKD [1]. In view of the fact that albuminuria is an independent renal and cardiovascular risk factor, their data point out underpinning mechanisms through which RDN can mitigate the renal and cardiovascular risk in those patients. 
Fig. 1 Numerous types of renal injury can trigger increased afferent signalling, which is centrally integrated leading to increased sympathetic discharges to various organs, including the kidneys, and thereby stimulating renin secretion, $\mathrm{Na}^{+}$retention and vasoconstriction. The increased sympathetic output is also pointed towards other relevant organs (e.g. the heart and peripheral vessels), which can result in adverse outcomes. RAAS, reninangiotensin-aldosterone system; $\mathrm{Na}^{+}$, sodium; $\mathrm{O}_{2}$, oxygen. Adapted from [10]. Reproduced with permission
Kidney as Origin of Central Sympathetic Activity

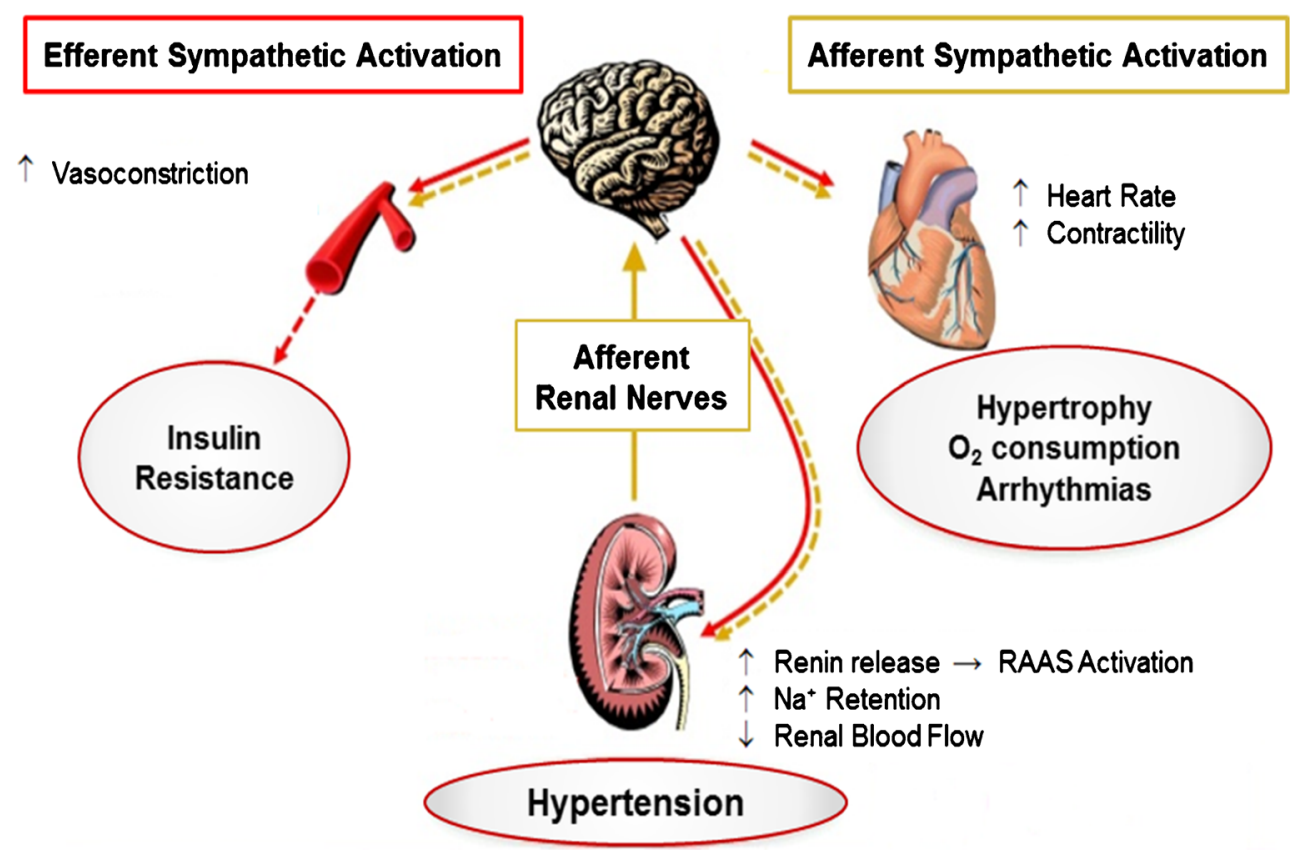

All in all, merging their favourable pre-clinical results with currently available clinical data provides a strong incentive to further explore catheter-based RDN as a therapeutic approach in CKD and other diseases related to sympathetic hyperactivity.

\section{Compliance with ethical standards}

Conflict of interest MPS is supported by an NHMRC Research Fellowship and has received consulting fees, and/or travel and research support from Medtronic, Abbott, Novartis, Servier, Pfizer, and Boehringer-Ingelheim. All other authors declare that they have no conflict of interest.

\section{References}

1. Gansevoort RT, Correa-Rotter R, Hemmelgarn BR, Jafar TH, Heerspink HJ, Mann JF, Matsushita K, Wen CP (2013) Chronic kidney disease and cardiovascular risk: epidemiology, mechanisms, and prevention. Lancet 382:339-352. https://doi.org/10.1016/ S0140-6736(13)60595-4

2. Grassi G (2009) Assessment of sympathetic cardiovascular drive in human hypertension: achievements and perspectives. Hypertension 54:690-697. https://doi.org/10.1161/HYPERTENSIONAHA.108. 119883

3. Grassi G (2010) Sympathetic neural activity in hypertension and related diseases. Am J Hypertens 23:1052-1060. https://doi.org/10. 1038/ajh.2010.154

4. Grassi G, Mark A, Esler M (2015) The sympathetic nervous system alterations in human hypertension. Circ Res 116:976-990. https:// doi.org/10.1161/CIRCRESAHA.116.303604
5. Kiuchi MG, Maia GL, de Queiroz Carreira MA, Kiuchi T, Chen S, Andrea BR, Graciano ML, Lugon JR (2013) Effects of renal denervation with a standard irrigated cardiac ablation catheter on blood pressure and renal function in patients with chronic kidney disease and resistant hypertension. Eur Heart J 34:2114-2121. https://doi. org/10.1093/eurheartj/eht200

6. Lopes NR, Milanez MIO, Martins BS, Veiga AC, Ferreira GR, Gomes GN, Girardi AC, Carvalho PM, Nogueira FN, Campos RR, Bergamaschi CT, Nishi EE (2020) Afferent innervation of the ischemic kidney contributes to renal dysfunction in renovascular hypertensive rats. Pflugers Arch:1-10. https://doi.org/10.1007/ s00424-019-02346-4

7. Matsushita K, van der Velde M, Astor BC, Woodward M, Levey AS, de Jong PE, Coresh J, Gansevoort RT, Chronic Kidney Disease Prognosis C (2010) Association of estimated glomerular filtration rate and albuminuria with all-cause and cardiovascular mortality in general population cohorts: a collaborative meta-analysis. Lancet 375:2073-2081. https://doi.org/10.1016/S0140-6736(10)60674-5

8. McGrath BP, Ledingham JG, Benedict CR (1978) Catecholamines in peripheral venous plasma in patients on chronic haemodialysis. Clin Sci Mol Med 55:89-96

9. Ott C, Mahfoud F, Schmid A, Ditting T, Veelken R, Ewen S, Ukena C, Uder M, Bohm M, Schmieder RE (2014) Improvement of albuminuria after renal denervation. Nephrol Dial Transplant 29:9-9

10. Schlaich MP, Sobotka PA, Krum H, Whitbourn R, Walton A, Esler MD (2009) Renal denervation as a therapeutic approach for hypertension novel implications for an old concept. Hypertension 54: 1195-1201. https://doi.org/10.1161/Hypertensionaha.109.138610

11. Schlaich MP, Socratous F, Hennebry S, Eikelis N, Lambert EA, Straznicky N, Esler MD, Lambert GW (2009) Sympathetic activation in chronic renal failure. J Am Soc Nephrol 20:933-939. https:// doi.org/10.1681/ASN.2008040402

Publisher's note Springer Nature remains neutral with regard to jurisdictional claims in published maps and institutional affiliations. 